\title{
FATTY ACIDS PATTERN OF OLIVE OIL UNDER ORGANIC FARMING
}

\author{
${ }^{1}$ Nasab Al-Rawashdeh and ${ }^{2}$ Fawzi Al-Sheyab \\ ${ }^{1}$ National Center for Agriculture Research and Extension (NCARE), Jordan \\ 2Jordan University of Science and Technology (JUST), Jordan
}

Received 2013-07-24; Revised 2014-03-30; Accepted 2014-04-16

\begin{abstract}
Organic farming is considered as a mitigation strategy to face adverse effect of climate change and Consumers' increasing their need for safe and quality food has motivated this research study. The olive oil of the Roman olive trees (Landrace) Olea Europea belong to the Oleaceae family growing under organic farming (in the transition period) conditions in Jordan Ajlun area was extracted by traditional method; warming water to the about $60^{\circ} \mathrm{C}$ and grounded the seeds make as paste then pour in the warmed water then take the oil layer floated at the surface. The oil was analyzed for fatty acids pattern and compared with Romans trees olive oil grown at Burma Agriculture Station which has organic Certificate according to the Japanese Agriculture Standard (JAS) since 2007. The separation patterns of fatty acids were done by Gas Chromatography (GC). Results showed high levels of unsaturated fatty acids, particularly oleic acid (up to 67.49\%), linoleic acid $(13.31 \%)$ and linolenic acid $(0.74 \%)$ in the oil of Romans trees growing in Ajlun area, while the organic olive oil from the Romans olive trees growing at Burma Station showed $68.88 \%$ of oleic acid, $11.73 \%$ of linoleic acid and $0.67 \%$ of Linolenic acid. The analysis also showed that the palmatic saturated fatty acid was $12.54 \%$ at Burma Station compared to $11.82 \%$ in Ajlun area. The medicinal value of unsaturated fatty acids play great role for reducing cholesterol rate that was found in high level of Romans olive trees (landrace).
\end{abstract}

Keywords: Fatty Acids, Jordan, Olive Oil, Organic Farming, Romans Olive (Landraces) Trees

\section{INTRODUCTION}

Olive tree is the most important fruit tree grown in Jordan. It covers about $72 \%$ of the total area planted with fruit trees and $36 \%$ of the total cultivated area. Area covers now around 126,000 ha (MOA, 2006). The main producing areas are; the western mountains that cross the country from north to south (rainfed) which represent about $76 \%$ of the total area planted with olive and the north eastern region (irrigated) which represents about 24\% (MOA, 2006).

The major producer of olive oil in the world is the European Union (EU), which produces $80 \%$ and consumes 70 per cent of the world's total olive oil production (EC, 2012).

Italy and Spain are the major producers and can influence the prices of olive oil (Blery and Sfetsiou, 2008). Greece takes third place in world production after Spain and Italy (Ristel Edimo 2013) olive oil considered Corresponding Author: Nasab Al-Rawashdeh, National Center for as a traditional food product some important associations between the consumption of such traditional products and cultural aspects such as values, beliefs and life-style orientations (Vanhonacker et al., 2010). olive oil fatty acids are the most important components in olive oil with the majority of fatty acid chains contain 16-18 carbon atoms-shown as ' $\mathrm{C} 16$ ' and ' $\mathrm{C} 18$ ' respectively (hht/www.saylor.org/site/wp../2010/11/Wiki Triglyceride). Olive polyphenols are also bioactive against specific cancer lines (Obied et al., 2009) on the other hand Psaltopoulou et al. (2011) found that olive oil intake is inversely related to cancer prevalence.

New olive oil consumers seem to be more interested in olive oil for two main reasons: Health benefits and flavor (Santosa, 2010). Studies have also distinguished clear associations between reduced rates of certain types of cancer and increased olive oil consumption. Among health benefits, lowering the risk of coronary disease, 
preventing certain kinds of cancer (Konstantinidou et al., 2010) Nevertheless, it is true that there other cheaper seed oils being used as substitutes (Bernabeu et al., 2009). Prices of olive oil vary according to supply and demand, Prices differ for various reasons and particularly reflect the quality of olive oil. EC (2012) for instance, virgin and extra-virgin olive oils are more expensive than standard olive oil. With regard to flavor (Santosa and Guinard, 2011) Jordanian Extra Virgin Olive oils have some characteristics that distinguish it; an aroma of ripe olives with hints of apple and other mature fruits with almost total absence of bitterness (http://www.vipj.com/index.html).

On the other hand Olive farming provides an important source of employment in many rural areas of the Mediterranean, including many marginal areas where it is either a principal employer or an important part-time employer. Olive farming is also an important part of local rural culture and heritage in many areas, (ec.europa.eu/environment).

Organic farming is widely perceived as being more environmentally friendly than conventional farming. As a form of sustainable agriculture, it receives substantial support from policy for its contribution to environmental protection as well as the provision of amenities such as biodiversity and cultural landscapes (Darnhofer et al., 2010).

Permaculture offer positive solutions to the environmental and agricultural problems. This agricultural methods use ecology as the basis of designing integrated systems of food production (Mollison and Tagari, 1991). Organic farming works in harmony with nature rather than against it. This involves using techniques to achieve good crop yields without harming the natural environment or the people who live and work in it. Organic production essentially excludes the use of many inputs associated with modern farming, most notably synthetic pesticides and fertilizers. To the maximum extent possible, organic farming systems rely upon crop rotations, crop residues, animal manures, legumes, green manures, off-farm organic wastes, mechanical cultivation, mineral-bearing rock powders and biological pest control. These components maintain soil productivity and tilt, supply plant nutrients and help to control insects, weeds and other pests (Kristiansen and Merfield, 2006).

\subsection{Objectives:}

- Analysis of fatty acids pattern under transition period of organic production compared with the international standard and organic olive oil produced in Burma station taken certificate since 2007
- Is there variation in the fatty acids pattern under organic and transition period to organic production system?

- Introduction of organic farming techniques in the rural area

- Raising awareness and promotion of the historical (Roman) olive trees and the oil quality of these trees. Qualifying for organic certification

\section{MATERIALS AND METHODS}

The olive oil of the Romans olive trees growing under organic farming (in the second year of the transition period) conditions in Ajluon area Fig. 1 were extracted by traditional method. Warming water up to $60^{\circ} \mathrm{C}$ and ground the seeds to paste then pour on warm water separate the oil layer floating on the surface and compared with the olive oil of Romans trees grown at Burma Agriculture Station in Jarash governorate (about $45 \mathrm{~km}$ to the north of Amman) is the target areas for the permaculture project that was implemented in cooperation between Japan International Cooperation Agency (JICA), Nippon International Cooperation for Community Development (NICCOD) and Ministry of Agriculture in Jordan for 3 years that was starting in 2004. Alhashimeh in Ajlun Governorate about $70 \mathrm{~km}$ to the north west of Amman) 20 ha planted with old trees is the target areas for the organic production project that was implemented in cooperation with National Center for Agriculture Research and Extension (NCARE) and farmers in Ajlun/Alhashimeh governorate about 0.5 hectar selected and applied the organic production system for about 3 years started in the year 2008. The oil was analyzed for fatty acids pattern. The separation pattern of fatty acids olive oil analyzed using Gas Chromatography (GC) machine at the Royal Scientific Association/Jordan the analysis was done according to COI/T.20/Doc.No.24 (2001).

\subsection{Methods Used:}

- Awareness program throughout lectures and training of the interested ones. They contacted farmers in the district during the awareness program

- Training farmers on organic farming rules and aspects that leading them to organic product and get the organic farming certificate

- Main practices used was including the following: Spreading environmentally friendly organic farming methods as follows 
- Water management techniques, include rock basins for water harvesting

- Soil management techniques, including compost making and mulching leading to soil conservation and fertility improvement

- Mix planting, including green (living) mulch to prevent evaporation and soil erosion, leguminous plants to improve soil fertility and $\mathrm{N}$-fixation, repellent plants as Neem tree (Nema indica), pest control using traps and parasite system and polyculture plantation for biodiversity

- Creating awareness among farmers in the target area

- Establishing a model farm (Demonstration) to implement all the

- Permaculture (organic farming) methods

- Improving the economic productivity of low-income farmers through

- Reducing the cost of production inputs by using the natural resources

- Introducing animal keeping activity such as chicken livestock

- Encouraging farmers in the target area to establish cooperative group(s) to work to reduce the cost of organic farming and upgrade the quality of organic olive oil
- Raising awareness and promotion of the historical (Roman) olive trees and oil quality

\section{RESULTS}

Fatty acid compositions of the olive oil under organic farming system and in the transition period to the organic production were analyzed are presented in Table 1. The major saturated fatty acids in all oils were palmitic and stearic acids; the main unsaturated fatty acid were oleic and linoleic acid. Experiments revealed the oils tested contained large amounts of unsaturated fatty acids. The most abundant was the mono-unsaturated oleic acid (C18:1), approximately $68 \%$ in olive oil. This means the fats tested are significant sources of unsaturated fatty acids. All the studied oil samples contain the oleic and linoleic acids, these oils can be classified in the oleic-linoleic acid group (Kimbonguila et al., 2010) Table 1.

Olive oil under transition period at Ajlun Governorte showed high percentage of Oleic acid (67.49\%), Palmitic acid (11.82\%), linoleic acid (13.31), Stearic acid and $(4.35 \%)$ and organic olive oil at Burma Station of oliec acid $(68.88 \%)$ palmatic acid $(12.54 \%)$, linoleic acid (11.73\%), Stearic acid and (3.97\%) Fig. 2.

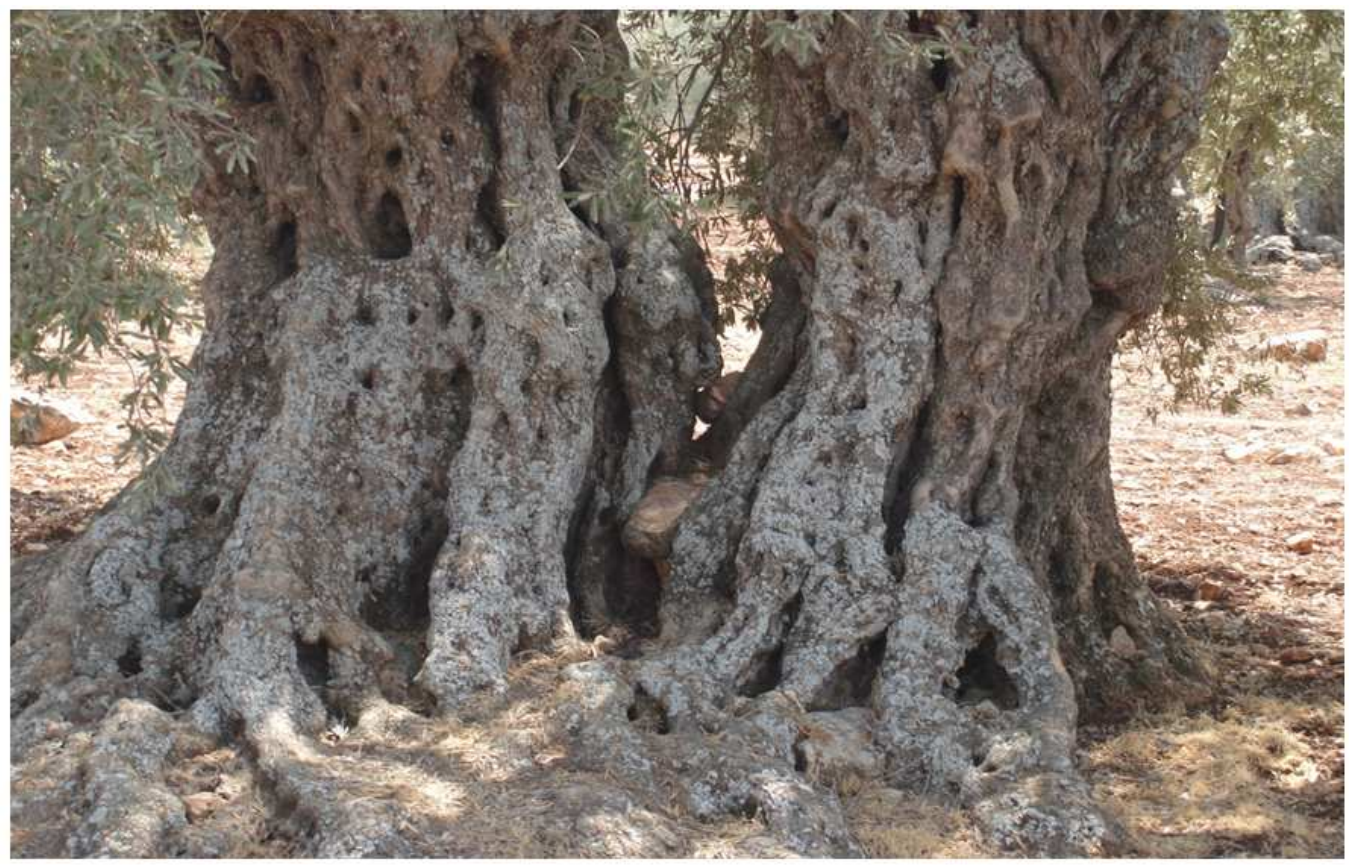

Fig. 1. Old Romans olive tree in Jordan/Ajluon Alhashmeah 


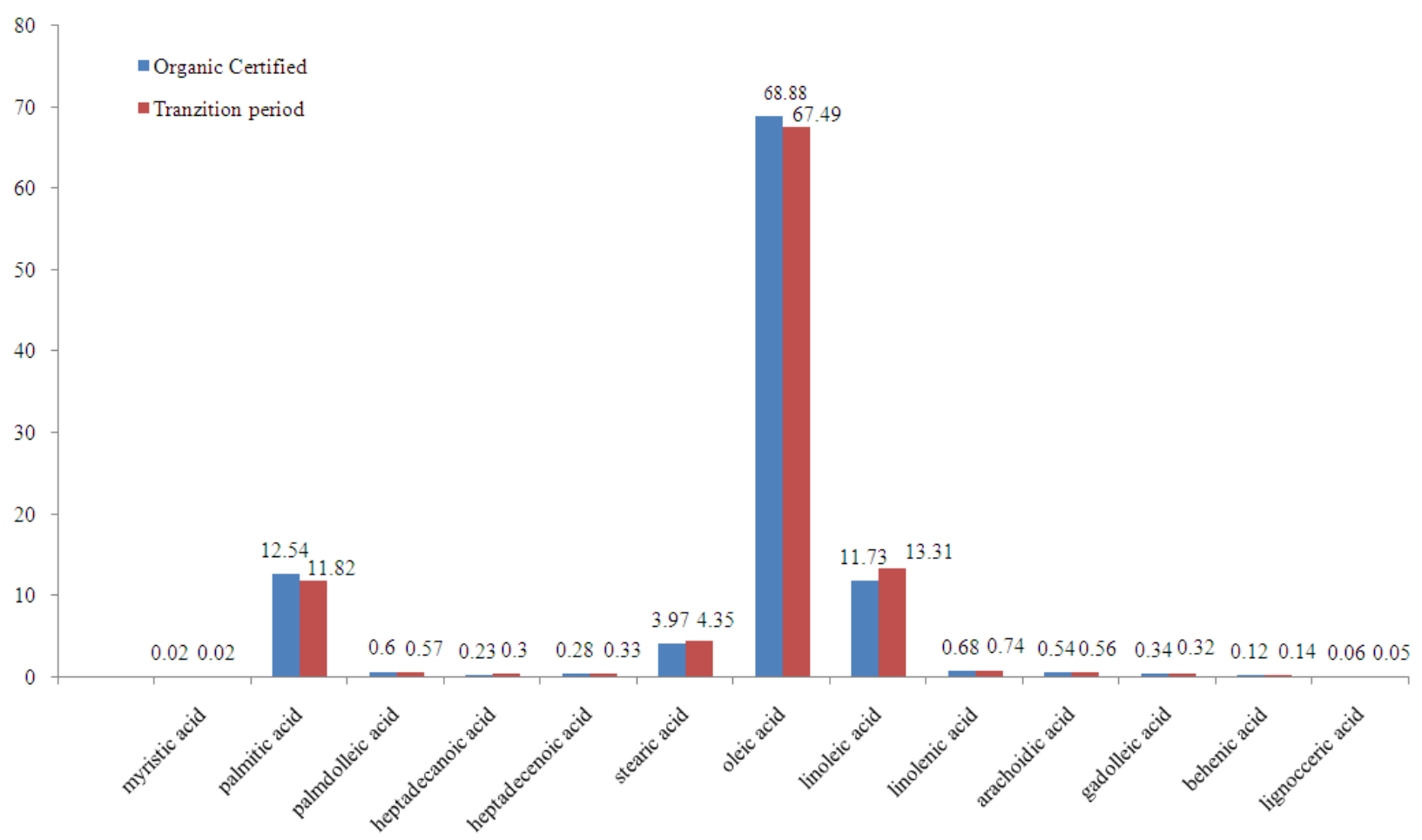

Fig. 2. Analysis of Roman olive oil under different farming system

Table 1. Fatty acids composition of Romans olive oil under tow farming system

\begin{tabular}{|c|c|c|c|c|}
\hline \multicolumn{2}{|c|}{$\begin{array}{l}\text { Fatty acids fatty acids name } \\
\text { olive oil composition }\end{array}$} & \multirow{2}{*}{$\begin{array}{c}\begin{array}{c}\text { Olive oil/Burma } \\
\text { (Organic certified) }\end{array} \\
0.02\end{array}$} & \multirow{2}{*}{$\begin{array}{l}\begin{array}{l}\text { Olive oil/Ajlun } \\
(\text { Tranzition period) Unite \% }\end{array} \\
00.02\end{array}$} & \multirow{2}{*}{$\frac{\text { Standared refined }}{00.0-0.05}$} \\
\hline C14:0 & myristic acid & & & \\
\hline C16:0 & palmitic acid & 12.54 & 11.82 & $07.5-20.0$ \\
\hline C16:1 & palmdolleic acid & 0.60 & 0.57 & $00.3-3.5$ \\
\hline C17:0 & heptadecanoic acid & 0.23 & 0.30 & $00.0-0.3$ \\
\hline C17:1 & heptadecenoic acid & 0.28 & 0.33 & $00.0-0.3$ \\
\hline C18:0 & stearic acid & 3.97 & 4.35 & $00.5-5.0$ \\
\hline C18:1 & oleic acid & 68.88 & 67.49 & $55.0-83.0$ \\
\hline C18:2 & linoleic acid & 11.73 & 13.31 & $03.5-21.0$ \\
\hline C18:3 & linolenic acid & 0.68 & 00.74 & \\
\hline C20:0 & arachoidic acid & 0.54 & 00.56 & $00.0-0.6$ \\
\hline C20:1 & gadolleic acid & 0.34 & 00.32 & $00.0-0.4$ \\
\hline $\mathrm{C} 22: 0$ & behenic acid & 0.12 & 00.14 & $00.0-0.2$ \\
\hline $\mathrm{C} 24: 0$ & lignocceric acid & 0.06 & 00.05 & $00.0-0.2$ \\
\hline
\end{tabular}

\section{DISCUSSION}

Olive oil tree is mentioned in all religious it is a blessed tree Olive oil fatty acid composition in the rainfed are as in Ajlun Governorate in the studied area show the same composition of the organic olive oil at Burama Station both have high percentage of unsaturated fatty acid. Oils that have high levels of monounsaturated oleic acid are considered to be of highest nutritive value (oleic acid is named after olive 'olea' On the other hand, olive oil contains considerable $\mathrm{C} 18: 2$ which is polyunsaturated and contributes to the instability of the oil (Mailer, 2006). The International Olive Council (IOC) has produced a list of the allowable levels for each of the fatty acids to be acceptable as extra virgin olive oil, the percentage of fatty acids found by oil of Romans olive trees in Jordan, based on this study, was with 
allowable levels and can be considered as an extra virgin olive oil.

Gulfraz et al. (2009) reported that the concentration of fatty acids of wild olive were; oleic acid (69.3-74.5\%), linoleic acid (1.3-3.2\%), linolenic acid (11.2-15.2\%) palmitoleic acid (1.10-2.10\%), palmitic acid (11.2-14.0\%) and stearic acid $(0.1-0.2 \%)$. On the basis of the present study the fatty acid compositions of Rumania olive oil suggested that the oleic acid concentration was the highest among the others.

\section{CONCLUSION}

Experiments revealed that the oils tested contained large amounts of unsaturated fatty acids. The most abundant was the mono-unsaturated oleic acid (C18:1), approximately $68 \%$ in olive oil under different farming system show very little bit differences for both organic and transition period of real promise for Jordan olive oil quality. Small differences in the percent of fatty acids might be consider as geographical indicators. Jordan's olive oil has high percent of unsaturated fatty acids which is considered as quality standard for olive oil and play great role in medicinal uses. future prospects of the research, the working is required for studying all characteristics of the olive oil under different farming system and other varieties of olive and other crops, dispersal public awareness of the organic farming systems to improve food quality and safe the environment.

\subsection{Recommendation}

In situ and ex situ conservation of Romans olive tree populations are powerfully recommended to reduce major threat of the trees like uprooting and using tree in the landscaping and the tree exposing to wooding and fire on the other hand, Implementing simple practices that could be copied in other areas of Jordan and encouragement of farmer-based extension; it is recommended to end user the Romans trees have high quality oil especially in the monounsaturated fatty acid oliec acid and linoleic acid they considered as quality standard for olive oil, rainfed planting of olive trees in Jordan easy to transferred to organic production with very good olive oil quality in terms of fatty acids composition.

\section{ACKNOWLEDGMENT}

Author thank the Director General of National Center For Agriculture Research and Extension Dr. Faisal
Awawdeh Alshiaub for the continuous support and encourgement thank also for the Farmers in Ajlun and thanks extended for Engineear Yahya Abu Saeni for his cooperation and for Burma Station Staff in the study area for their cooperation.

\section{REFERENCES}

Bernabeu, R., M. Olmeda, M. Díaz and R. Olivas, 2009. Oportunidades comerciales para el aceite de olive de Castilla-La Mancha. Grasasy Aceites, 60: 525-533. DOI: $10.3989 /$ gya.053409

Blery, E. and E. Sfetsiou, 2008. Marketing olive oil in Greece. Br. Food J., 110: 1150-1162. DOI: 10.1108/00070700810918045

Darnhofer, I., T. Lindenthal, R. Bartel-Kratochvil and W. Zollitsch, 2010. Conventionalisation of organic farming practices: From structural criteria towards an assessment based on organic principles. A review. Agronomy Sustainable Dev., 30: 67-81.

EC, 2012. Directorate-general for agriculture and rural development Economic analysis of the olive sector. European Commission.

Gulfraz, M., R. Kasuar, G. Arshad, S. Mehmood and N. Minhas et al., 2009. Isolation and characterization of edible oil from wild olive. Afr. J. Biotechnol., 8: 3734-3738.

Kimbonguila, A., J.M. Nzikou, L. Matos, B. Loumouamou and C.B. Ndangui et al., 2010. Proximate composition of selected congo oil seeds and physicochemical properties of the oil extracts. Res. J. Applied Sci. Eng. Technol., 2: 60-66.

Konstantinidou, V., M.I. Covas, D. Muñoz-Aguayo, O. Khymenets and G. Saez et al., 2010. In vivo nutrigenomic effects of virgin olive oil polyphenols within the frame of the Mediterranean diet: A randomized controlled trial. FASEB J., 24: 2546-57. PMID: 20179144

Kristiansen, P. and C. Merfield, 2006. Overview of Organic Agriculture. In: Organic Agriculture: A Global Perspective, Kristiansen, P., A. Taji and J. Reganold (Eds.)., CSIRO Publishing, Collingwood, ISBN-10: 0643099395, pp: 1-23.

Mailer, R., 2006. Chemistry and quality of olive oil. PRIMEFACT 227

MOA, 2006. Annual agricultural statistics-2006. Jordan Ministry of Agriculture, Organic Agriculture: A Global Perspective, Amman. 
Mollison, B. and R.M.S. Tagari, 1991. Introduction to Permaculture. 2nd Edn., Tagari Publications, Tyalgum, ISBN-10: 0908228058, pp: 198.

Obied, H.K., P.D. Prenzler, I. Konczak, A.U. Rehman and K. Robards, 2009. Chemistry and bioactivity of olive biophenols in some antioxidant and antiproliferative in vitro bioassays. Chem. Res. Toxicol., 22: 227-234. PMID: 19099401

Psaltopoulou, T., R.I. Kosti, D. Haidopoulos, M. Dimopoulos and D.B. Panagiotakos, 2011. Olive oil intake is inversely related to cancer prevalence: A systematic review and a metaanalysis of 13,800 patients and 23,340 controls in 19 observational studies. Lipids Health Dis., 10: 127-127. DOI: 10.1186/1476-511X-10-127, PMID: 21801436
Ristel Edimo, 2013. Le Maroc est sixième producteur mondial d'huile d'oliv.

Santosa, M. and J.X. Guinard, 2011. Means-end chains analysis of extra virgin olive oil purchase and consumption behavior. Food Q. Preference, 22: 304316. DOI: 10.1016/j.foodqual.2010.12.002

Santosa, M., 2010. Analysis of sensory and non-sensory factors mitigating consumer behavior: A case study with extra virgin olive oil. $\mathrm{PhD}$ Thesis, Food Science, University of California, Davis.

Vanhonacker, F., V. Lengard, M. Hersleth and W. Verbeke, 2010. Profiling European traditional food consumers. British Food J., 112: 871-886. DOI: 10.1108/00070701011067479 ISBN: 0007-070X 